\title{
Professor Judith S. Stern: April 25, 1943-May 8, 2019
}

\author{
Richard L. Atkinson $\mathbb{1}^{1} \cdot$ Barbara C. Hansen $\mathbb{B}^{2}$
}

Received: 25 June 2019 / Accepted: 30 June 2019 / Published online: 2 August 2019

(c) The Author(s), under exclusive licence to Springer Nature Limited 2019

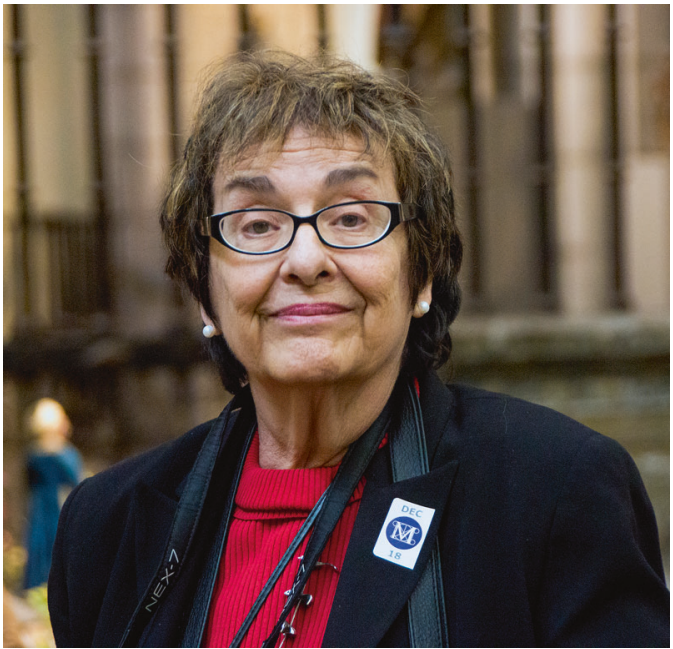

Dr. Judith S. Stern was one of the pioneers in the field of obesity research and a founding member of the North American Association for the Study of Obesity (NAASO, now The Obesity Society). She was born in Brooklyn, NY, USA, and in 1964 graduated from Cornell University, where she received her B.S., with honors, in Food and Nutrition, and was certified as a Registered Dietitian. She attended the Harvard School of Public Health and completed the Sc.M. in Nutrition in 1966 and the Sc.D. in 1970. She was a student under Dr. Jean Mayer at Harvard. She then entered the laboratory of Dr. Jules Hirsch at the Rockefeller Institute to continue her obesity and nutrition research. After her Postdoctoral Fellowship she was appointed as Assistant Professor. In 1974, she accepted a faculty position as Assistant Professor of Nutrition at the

Richard L. Atkinson

ADV36lab@Gmail.com

1 Virginia Commonwealth University School of Medicine: Endocrine/Metabolism, Manakin-Sabot, VA, USA

2 University of South Florida, College of Medicine: Internal Medicine and Pediatrics, Tampa, FL, USA
University of California, Davis, where she continued until her death, rising to the position of Distinguished Professor of Nutrition and Internal Medicine and retiring as Emerita Professor.

When Dr. Stern started her career, the field of obesity hardly existed, and she was a part of the founding of what is now the specialty of Obesity Medicine. Her early research focused on the endocrine mechanisms of adipose tissue cellularity and the molecular, biochemical, and physiological differences of obese Zucker fatty rats. She started a Zucker rat breeding facility at UC Davis and carried out a comprehensive series of studies on all aspects of these animals. Other studies involved rats with hypothalamic lesions for evaluation of changes in energy intake and expenditure, endocrine/metabolic function, and alterations of body weight. She began studies in humans, focusing on evaluation of responses to diet, exercise, treatment of obesity, and later into the role of alternative medicine in obesity and nutrition. Her studies ranged across the lifespan from children to the elderly. She also focused on policy and advocacy issues and became an ardent advocate for people with obesity.

Dr. Stern joined and contributed to numerous professional organizations, including the American Association for the Advancement of Science, American Diabetes Association, American Dietetic Association (now the Academy of Nutrition and Dietetics), American Heart Association, American Obesity Association (AOA), American Society for Clinical Nutrition (now American Society for Nutrition), and the NAASO, now The Obesity Society. In 1995 she was elected to the National Academy of Sciences Institute of Medicine, now the National Academy of Medicine. Dr. Stern was a lively presence and leader in many of these organizations. She was elected to major leadership roles, including being President of NAASO and of the American Society for Clinical Nutrition, and being Co-founder and Vice-President of the AOA. AOA was established as a lay-professional organization to advocate for obesity: patients, obesity drugs, physicians, scientists, and research. She was highly active and helped AOA to 
successfully lobby for changes in government policy regarding tax exemptions for obesity treatment, inclusion of obesity as a critical priority for the US Surgeon General and $\mathrm{NIH}$, and for inclusion of obesity as a disease by the Centers for Medicare \& Medicaid Services. For her work in this public service The Obesity Society established the annual Atkinson-Stern Award for Distinguished Public Service. Recipients of the Atkinson-Stern Award have included President Bill Clinton and First Lady Michelle Obama.

In additional to her obesity advocacy work, a major focus of Dr. Stern's life was her dedication to students and trainees. She mentored three generations of students, fellows, and young investigators during her tenure at UC Davis. She brought joy, inspiration, and energy to all of her mentees. Many of her mentees went on to occupy positions in university faculties and important positions in the healthcare industry. Her life was dedicated to improving the lot of all people, particularly young people and those disadvantaged. Judy and her husband, Dick, traveled to meetings around the world in providing leadership to the obesity world. Their 54-year marriage was a visible testimony to a dedicated and loving couple. Judy's contributions to the early foundations of obesity research, treatment, advocacy, and policy have been massive, and her colleagues, family, and students will miss her expertise, her great dedication, and especially her humor. 